\title{
Sustainable Transportation in Saudi Arabia: Reducing Barriers and Choosing Values
}

\author{
Dr Attiyah M Al-Atawi \\ Associate Professor, Faculty of Engineering, University of Tabuk
}

\begin{abstract}
One of the main barriers to achieving a sustainable transportation system in Saudi Arabia is low petrol prices that make public transport an undesirable travel option in the country. The private vehicle is very much a cost-effective means of transportation within the region and will remain so for some time to come. It is very important, therefore, to investigate factors that affect travel behaviour and travel decisions in Saudi Arabia and to investigate attitudes to sustainability in order to devise the right policies to aim for sustainability. It is also important to raise awareness about environmental problems, about the impact of traffic on sustainability and about the role of public transport in achieving this sustainability. The aim of this paper is to investigate the level of awareness of sustainability in Tabuk city in Saudi Arabia and to assess attitudes and preferences towards measures and policies that aim to achieve sustainability. The paper makes a contribution to our understanding of transport attitudes and transport behaviour in Saudi Arabia within the framework of the sustainability issues and with reference to critical gender particularities of the case location.
\end{abstract}

\section{Introduction}

The use of motorised transport'supports sustained local economic growth but also raises issues of safety, health, road fatalities, traffic and congestion, and detrimental environmental impacts (Howard and Polyviou, 2012). Numerous definitions of sustainability and sustainable transport have been offered in which a common underlying theme is the desire to balance competing needs among economic, social and environmental issues as stated in Steven et al., 2013. Sustainable transport issues are both common to and vary between developed and developing countries (Amekudzi and Vanegas, 2006). Devuyst and Van Volsem (2001) drew attention to the need for an instrument of evaluation that could be used to assess the impact of household travel behaviour on the overall sustainability of lifestyle.

In view of limited technical advances and efficiency improvements, along with growing traffic volumes, behavioural changes towards more sustainable travel futures have become crucial (Prillwiz and Barr, 2011). In order for a transportation system to be sustainable it must meet the needs of the users under the areas of economy, society and environment - the three pillars of sustainability. What this means is that for a system to be truly sustainable, it must meet the social and economic needs of the user while also limiting the environmental impact. In this paper, it is hoped to examine how the general public within Saudi Arabia views more environmentally friendly modes of transport that could reduce emissions within the country. The overall sustainability of these systems is called into question as they often result in higher costs and an inability to meet social demands when compared to that of the private vehicle. One of the main barriers to achieving a sustainable transportation system in Saudi Arabia is the fact that petrol prices remain low in the region leading to the private vehicle being a cost-effective means of transportation. Along with this, Islamic cultural restrictions on the movement of women result in the possibility of their social exclusion. They therefore mainly rely on male family members to drive them, or use a private driver. 
This paper attempts to assess the perception of sustainability and the attitudes of travellers towards alternative transportation policies in Tabuk city of Saudi Arabia.

\section{Awareness of Transport Sustainability}

Measures aiming to manage mobility face various levels of acceptance and implementation - despite the considerable contribution that they could make to reducing problems such as climate change. These variations are influenced by psychological factors like attitudes, and levels of habitualisation and convenience regarding potential behavioural changes (Prillwiz and Barr (2011). Recent research shows that attitudes towards the environment or environmentally friendly transport modes can influence mode choice towards more sustainable mobility on a daily basis (e.g., Hunecke et al., 2007), but environmental factors are considered less, or not at all, for holiday travel decisions (e.g., Becken, 2007).

Leiserowitz, Kates and Parris (2006) carried out a review of the values, attitudes and behaviours globally that influence the development of sustainability. Leisero et al., (2006) said that there were three main conclusions as to what was required to achieve sustainable development: accelerating action, bridging barriers, and choosing values. Accelerating action is described as the need to increase the rate of action in choosing more sustainable solutions to current activities. However, the authors indicate that there may need to be a global event to prompt the level of change required. Bridging barriers was described as the steps required to convert the expressed values and attitudes, or individuals, into actual behaviours. In order to overcome these barriers, authorities will need to address the specific barriers present in each situation and attempt to mitigate these as far as possible in order to make sustainability achievable (e.g., gender equality). Choosing values is a term used to highlight the fact that individuals have different value systems and that the majority of individuals and decision makers will need to have the ideal set of values in order for sustainability to become feasible (e.g., choosing a more expensive, cleaner fuel source over a cheaper, dirtier one).

A study by Anable et al., (2006) focussed on the link between public attitudes towards climate change and their mode choices in transportation. Anable et al., (2006), Grop (1995) Handy et al., (2005) and Wright and Egan (2000) demonstrated that there is a need to increase the public's knowledge of the link between transportation choices and the effect these decisions had on the environment. Their findings were also similar to those of Leiserowitz, Kates and Parris (2006). These studies address the need for a attitudinal investigations at individual basis, to incorporate the needs of all individuals when undertaking a journey in order to begin to change their attitude towards alternative and use more sustainable options. One of the methods put forward by Anable et al., (2006) to change travel behaviour was through the proper management of transport policies. It was argued that while these policies can be adapted to target attitude change directly, they could also be tailored to alter travel behaviour directly and hopefully in time attitudes will change as the benefits of alternate modes of transport are seen.

Luomi (2012) indicated that in Qatar (a country that has experienced a similar level of rapid modernisation) the wealth and population growth experienced within the country has lead to a rapid alteration in individuals' behaviour, leading to unsustainable situations. One issue highlighted was the fact that Qatar Petroleum still identified itself as a fossil fuel company. This company has strong ties with the Department of Energy within the country and as a result there is little drive to promote sustainable energy sources within the country. Along with this, many people see the measures in place as being too weak and lacking any real ambition.

As the oil-producing company Saudi Aramco, operating in Saudi Arabia, is state owned (Saudi Aramco, 2013), it is realistic to assume that the issues outlined by Luomi (2012) are also valid in Saudi Arabia. The fact that this state-owned company depends so 
highly on the consumption of fossil fuels, and therefore needs continued consumption of fuel sources, will outweigh the need to adapt more sustainable systems within the country as a whole, especially within the transportation industry.

\section{Data Collection}

1200 questionnaires were distributed within the Tabuk city of Saudi Arabia as part of a large travel-behaviour survey undertaken in the city. From these distributed questionnaires, 515 responses were received which gave an overall response rate of 42.92 $\%$ (see Attiyah and Saleh 2013). In this questionnaire the respondents were asked a series of questions about their views on measures aiming to improve the overall sustainability of the transportation systems within Tabuk. As part of the data collection, respondents were asked to rate how they felt about pollution from the traffic in the city, in relation to the effect it had on them. Respondents were also asked to express their attitudes to statements such as:

a) If public transport policies or pricing policies were introduced in Tabuk, I would be forced to change my travel behaviour.

b) If public transport modes were introduced in Tabuk, I would choose to use other forms of transport rather than my car to travel to work.

Furthermore, respondents were asked to express their preferences and attitudes towards revenues raised, should any charges be introduced for driving and entering the central areas of the city, including spending on improving public transport or environmental issues. Knowing that public transport and environmental issues are low on the national agenda in Saudi Arabia, this type of investigation seemed relevant and important.

Respondents were then presented with a total of six options (Serious problem, Moderate problem, Neutral, Slight problem, No problem, Don't know) to rate the how much the issue affected them. The respondents were also asked to provide personal data. This was used in conjunction with the responses to the sustainability questions to determine how sustainability is perceived in the Tabuk area of Saudi Arabia and the influence that certain personal attributes have on this perception.

\section{Data Analysis}

The first question about the sustainability of the transportation system within the city asked respondents to rate how they felt about pollution from traffic, in relation to the effect it had on them. The questionnaire presented the respondent with a total of six options. From cross-tabulation of this data with the gender of the respondents, it was seen that 209 male respondents (51.2\% of the total survey) chose the "serious problem" option, along with 109 women (26.7 \% of the total survey). A detailed summary of the observations is provided in Table 1.

Table 1. Responses to the Issue of Traffic Pollution Cross Tabulated with Gender Information

\begin{tabular}{|c|c|c|c|c|c|c|c|}
\hline Gender & $\begin{array}{c}\text { Serious } \\
\text { problem }\end{array}$ & $\begin{array}{c}\text { Moderate } \\
\text { problem }\end{array}$ & Neutral & $\begin{array}{c}\text { Slight } \\
\text { problem }\end{array}$ & $\begin{array}{c}\text { No } \\
\text { problem }\end{array}$ & $\begin{array}{c}\text { Don't } \\
\text { know }\end{array}$ & Total \\
\hline Male & 209 & 44 & 11 & 5 & 2 & 2 & 273 \\
\hline Female & 109 & 19 & 2 & 2 & 1 & 2 & 135 \\
\hline Total & 318 & 63 & 13 & 7 & 3 & 4 & 408 \\
\hline
\end{tabular}


When the data in Table 1 is analysed by gender, $76.6 \%$ (209) of male respondents said that there was a "serious problem" with pollution due to traffic in the city, while $80.7 \%$ (109) of females expressed the same level of concern. In total, $77.9 \%$ (318) of respondents indicated that this was a serious issue for them, with a further $15.4 \%$ (63) indicating that they felt it to be a "moderate problem". When responses to this question were cross tabulated with results regarding the family positioning of respondents, it was found that $33.4 \%$ of responses were from family heads, while a further $18.4 \%$ held the position of wife within their family unit. Eldest son and son positions within the family unit accounted for $9 \%$ (Attiyah and Saleh 2013). With respect to age, the highest response rate for the "serious problem" option was from people in the 26-30 the age group, followed by 31-35. This could be an indication that younger generations in Saudi Arabia are more aware of environmental problems. This is encouraging, of course, and a positive finding from this analysis.

A further cross tabulation of responses to this question was carried out with the income levels of individuals responding to the survey. Under the "serious option" category it was seen that, for the most part, lower income group respondents show more concern about environmental issues than higher income group individuals.

Respondents were then presented with a series of scenarios, where alternative modes of transportation were introduced in Tabuk, along with the possibility of increased costs for the use of private cars. For these scenarios the respondent was asked to identify the extent to which they agreed with statements presented to them, on a six-point scale. The statements that identified respondents' willingness to alter their behaviour for more sustainable options were as follows:

a. If public transport policies or pricing policies were introduced in Tabuk, I would be forced to change my travel behaviour.

b. If public transport modes were introduced in Tabuk, I would choose to use other forms of transport rather than my car to travel to work.

A total of 98 respondents indicated that they "strongly agreed" with statement (a), with $66(67.3 \%)$ of these respondents being male while the remaining $32(32.7 \%)$ were female. A full summary of the findings for this cross tabulation is provided in Table 2.

Table 2. Gender Cross Tabulation and Attitudes to Travel Behaviour Change

a) If public transport policies or pricing policies were introduced in Tabuk, I would be forced to change my travel behaviour.

\begin{tabular}{|c|c|c|c|c|c|c|c|}
\hline Gender & $\begin{array}{c}\text { Strongly } \\
\text { agree }\end{array}$ & Agree & Neutral & Disagree & $\begin{array}{c}\text { Strongly } \\
\text { disagree }\end{array}$ & $\begin{array}{c}\text { Don't } \\
\text { know }\end{array}$ & Total \\
\hline Male & 66 & 79 & 42 & 58 & 24 & 9 & 278 \\
\hline Female & 32 & 34 & 17 & 27 & 12 & 16 & 138 \\
\hline Total & 98 & 113 & 59 & 85 & 36 & 25 & 416 \\
\hline
\end{tabular}

Data for the male and female demographics was analysed in relation to the total responses of the each gender type $28.4 \%$ (79) of male respondents indicated that they "agreed" with the statement, while a further 66 (23.7\%) indicated that they "strongly agreed" with it. Within the female category, the "agree" option was selected by $24.6 \%$ (34) of respondents, indicating that they would be forced to change their travel patterns, with a further $23.2 \%$ (32) indicating that they "strongly agree" with this statement.

In total, $27.2 \%$ of respondents agreed with the statement while $23.6 \%$ indicated that they "strongly agree" with it. Overall, $50.8 \%$ of respondents indicated that they would be 
forced to change their travel patterns should pricing policies be put in place within the city.

Cross tabulation of the results of this question was carried out in relation to the family position of the respondents. The "Agree" option was the most commonly chosen, with a total of 113 responses. The most common family position in this group was that of family head, representing $45(39.8 \%)$ of these responses, followed by the position of wife with $21(18.6 \%)$ responses. With respect to wives, there was an equal response rate in the "strongly agree" and "agree" options, each of which attracted 21 (22.1\%) responses. 20 $(21.1 \%)$ respondents indicated that they "disagreed" with the statement, with a further 14 $(14.7 \%)$ indicating that they felt neutral to the issue. There may be some bias in these responses due to the hypothetical nature of the questions. The data from question was cross tabulated with data provided by respondents about their age. The "strongly agree" option was the most commonly selected, with a total of 88 responses recorded in this section, which was highly correlated with the younger age group. Again, this might confirm the assumption that young people are more aware of environmental problems and more willing to do something about it. Further discussion of this is referred to in Attiyah and Saleh 2013.

In summary, a positive trend was seen in relation to this statement, which suggests that, should a more economical alternative be presented to individuals, they will choose it over their existing mode. However, this does not lead us to believe that sustainable alternatives will be readily taken up by the general public - it is only when they are presented with a substantial increase in the cost of their current mode that individuals indicate they would consider altering their travel behaviour.

\subsection{Perception in Relation to Sustainability Issues within Tabuk}

Respondent's perceptions of sustainability issues within the city were further investigated. In this case the individual was asked to indicate their level of agreement with statements such as: "I would be in favour of charging motorists to enter the city if the revenue raised was spent on tackling environmental pollution (caused by transport) or improving public transport". These statements deal with both an increase in the economic cost of undertaking a journey, along with activities to reduce the negative impacts of traffic. The responses to the statement are discussed. It can be seen from Table 3 below that the "strongly agree" and "agree" options are most commonly selected, by a total of 78 and 115 of respondents - under $50 \%$ of all respondents, and mostly male. The next most common option selected was the "neutral" option, selected by 84 of the respondents. Of these, $62(73.8 \%)$ were male.

Table 2. Gender Cross Tabulation with Attitudes to Public Transport Improvements

\begin{tabular}{|l|c|c|c|c|c|c|c|}
\cline { 2 - 8 } \multicolumn{1}{c|}{} & \multicolumn{6}{|c|}{$\begin{array}{l}\text { I would be in favour of charging motorists to enter the city if the } \\
\text { revenue raised was spent on introducing and improving public } \\
\text { transport. }\end{array}$} \\
\hline Gender & $\begin{array}{c}\text { Strongly } \\
\text { agree }\end{array}$ & Agree & Neutral & Disagree & $\begin{array}{c}\text { Strongly } \\
\text { disagree }\end{array}$ & $\begin{array}{c}\text { Don't } \\
\text { know }\end{array}$ & Total \\
\hline Male & 54 & 76 & 62 & 38 & 38 & 10 & 278 \\
\hline Female & 24 & 39 & 22 & 26 & 24 & 5 & 140 \\
\hline Total & 78 & 115 & 84 & 64 & 62 & 15 & 418 \\
\hline
\end{tabular}

In total, $46.2 \%$ of respondents to this question indicated that they were in favour of the proposed initiative, with $30.1 \%$ indicating that they disagreed with it to some extent. The 
data was cross tabulated with family positioning. The "agree" option attracted the highest number of responses, with 117 individuals selecting this option. Of these, family heads were the highest represented family position, accounting for $46(39.3 \%)$ of these responses, while the wife position accounted for a further $30(25.6 \%)$. In terms of age groups, once more the younger the age group, the more keen the individuals were to spend the revenues on public transport (Attiyah and Saleh 2013).

The cross tabulation of preferences to spend revenues on tackling environmental pollution and the gender of respondents is presented in Table 4 below. From this data it can be seen that the "agree" option was selected most often, with a total of 119 individuals selecting this option. $78(65.5 \%)$ of these responses were provided by males and $41(34.5 \%)$ by females. The "neutral" option was the second most popular response, with 99 individuals selecting this. $72(72.7 \%)$ of these were male. Table 4 provides a full summary of this cross tabulation data.

\section{Table 3. Gender Cross Tabulation with Attitudes to Environmental Pollution}

\begin{tabular}{|l|c|c|c|c|c|c|c|}
\cline { 2 - 8 } & \multicolumn{6}{c|}{$\begin{array}{l}\text { I would be in favour of charging motorists to enter the city if the } \\
\text { revenue raised was spent on tackling environmental pollution } \\
\text { (caused by transport) }\end{array}$} \\
\hline Gender & $\begin{array}{c}\text { Strongly } \\
\text { agree }\end{array}$ & Agree & Neutral & Disagree & $\begin{array}{c}\text { Strongly } \\
\text { disagree }\end{array}$ & $\begin{array}{c}\text { Don't } \\
\text { know }\end{array}$ & Total \\
\hline Male & 53 & 78 & 72 & 43 & 22 & 11 & 279 \\
\hline Female & 26 & 41 & 27 & 18 & 16 & 9 & 137 \\
\hline Total & 79 & 119 & 99 & 61 & 38 & 20 & 416 \\
\hline
\end{tabular}

When the data in Table 4 is analysed with respect to gender, it can be seen that, again, the majority of positive responses were provided by males, with 279 responses, while females gave 137 responses. The "agree" option was the most common response from males, accounting for $78(28 \%)$ of their responses, while the "neutral" response accounted for $72(25.8 \%)$. A total of $41(29.9 \%)$ female respondents indicated that they "agree" with the spending of revenue generated from charging individuals to enter the city on tackling pollution issues. $27(19.7 \%)$ female respondents indicated that they were neutral to the idea, while a further $26(19 \%)$ indicated that they "strongly agree" with it. In total, it was seen that $47.6 \%$ of respondents responded positively to this initiative while $23.8 \%$ disagreed with this initiative to some extent. $23.8 \%$ of overall respondents indicated that they were "neutral" to the idea while $4.8 \%$ indicated that they "don't know".

'The responses to this question suggest that the public is in favour of both means of spending revenue generated from charging motorists to enter the city A slightly higher proportion of the sample group (47.6 \%) is in favour of it being spent on tackling environmental pollution compared with the data for improving public transport within the city $(46.2 \%)$.

When these results are cross tabulated with family positioning, the family head position accounted for a total of 179 responses. $25.7 \%$ (46) of these selected the "agree" option, while $19.6 \%$ and $17.9 \%$ selected the "neutral" and "strongly agree" options respectively. 96 wives also provided a response to this question, with $31.3 \%$ (30) selecting the "agree" option while $17.7 \%$ (17) selected "disagree", and a further $17.7 \%$ (17) the "strongly disagree" option. $46.2 \%$ of respondents indicated that they "agree" with the statement to some extent while $30 \%$ indicated that they were opposed to the introduction of such a scheme.

In total, $46.6 \%$ of respondents indicated that they were in favour of spending revenue generated from charging motorists to enter the city if it was spent on tackling 
environmental pollution, while $25.7 \%$ were against such a proposal. $24 \%$ of those surveyed were against such a measure being implemented with $3.6 \%$ indicating they were undecided.

\subsection{Income Impacts and Perception of Respondents}

When cross tabulation results for responses to the statements above and income levels are compiled, the highest response rate relates to the "agree" option. Of these, 41 (33.6\%) came from individuals who stated that they had an income in the range of 4000-8000 SAR, with those in the 8001-12000 SAR range providing a further $38(31.1 \%)$ responses in the category.

The strongly agree response was the second most common, with 39 (43.8\%) coming from individuals in the 4000-8000 SAR pay range. The 8001-12000 SAR group contributed a further $24(27 \%)$ responses. From this analysis, no conclusion can be made on the impact of income on perceptions and attitudes to sustainability. It should be noted, however, that - as discussed earlier - the very low price of petrol in Saudi Arabia means that income is not a significant factor in attitudes and preferences on sustainability.

\section{Summary and Conclusion}

It is well acknowledged that the wealth and population growth being experienced in Saudi Arabia, along with neighbouring countries, has led to a rapid alteration in travel behaviour, leading to unsustainable travel decisions. The research conducted in this study found evidence of the public's awareness of environmental issues, public transport and sustainability. This was more evident in the younger population. Although this is very encouraging, there is still a need to increase the general public's awareness of the relationship between their transportation choices and the effect on the environment and sustainability. There is also the need to encourage use of public modes of transport and to raise awareness of their role in achieving sustainability. This can only be achieved through proper management of transport policies as well as raising awareness among the public.

This paper shows that when perceptions of different transport policies were evaluated and analysed based on socio-economic characteristics as discussed above, it was found that more than $78 \%$ agree or strongly agree that traffic is the reason for the pollution. More than $20 \%$ strongly agree that if public transport were to be introduced they would use it. Should transport policies or pricing policies be introduced in Tabuk, respondents stated that they would be forced to change their travel behaviour. Respondents also agreed that they would be in favour of charging motorists to enter the city if the revenue raised was spent on tackling environmental pollution (caused by transport).

The results obtained from this survey are crucial and encouraging. Although environmental issues and the role of public transport are said to be unimportant in Saudi Arabia and similar Gulf countries, the results obtained in this report show an increasing awareness of the environmental impacts of traffic. The impacts of education level, household structure and employment sector on attitudes to sustainability need further investigation and are recommended for future research. In addition, further research into road users' attitudes to transport policies and sustainability are still urgently needed in Saudi Arabia.

\section{References}

[1] M. A. Al-Atawi and W. Saleh, "Investigation and modelling of travel behaviour in Saudi Arabia: A disaggregate approach", Final Project Report, (2013).

[2] J. Anable, B. Lane and T. Kelay, "An evidence base review of public attitudes to climate change and transport behaviour", Final Report DfT. 
[3] S. Becken, “Tourists' perception of international air travel's impact on the global climate and potential climate change policies", Journal of Sustainable Tourism, vol. 15, no. 4, (2007), pp. 351-368.

[4] D. Devuyst and S. Van Volsem, "Sustainable lifestyle assessment", Devuyst, D., Hens, L., DeLannoy, W. (Eds.), How Green is the City? Sustainability Assessment and the Management of Urban Environments. Columbia University Press, NY, pp. 393-418.

[5] A. Grob, "A structural model of environmental attitudes and behaviour", Journal of Environmental Psychology, vol. 15, pp. 209-220.

[6] S. Handy, L. Weston and P. Mokhtarian, "Driving by choice or necessity", Transportation Research Part A, vol. 39, (2005), pp. 183-208.

[7] C. C. Howarth and P. Polyviou, "Sustainable travel behaviour and the widespread impacts on the local economy", Local Economy, vol. 27, no. 7, (2012) November, pp. 764-781.

[8] M. Hunecke, S. Haustein, S. Grischkat and S. Böhler, "Psychological, socio demographic, and infrastructural determinants of ecological impact caused by mobility behaviour", Journal of Environmental Psychology, vol. 27, (2007), pp. 277-292.

[9] J. Prillwitz and S. Barr, "Moving towards sustainability? Mobility styles, attitudes and individual travel behaviour", Journal of Transport Geography, ISSN 0966-6923, http://dx.doi.org/10.1016/j.jtrangeo.2011.06.011, vol. 19, no. 6, (2011) November, pp. 1590-1600.

[10] (http://www.sciencedirect.com/science/article/pii/S096669231100127X).

[11] A. A. Leiserowitz, R. W. Kates and T. M. Parris, "Sustainability Values, Attitudes, and Behaviours: A Review of Multinational and Global Trends", Annual Review of Environment and Resources, vol. 31, (2006), pp. 413-444.

[12] M. Luomi, "Qatar's Natural Sustainability: Plans, Perceptions, and Pitfalls", The Canter for International and Regional Studies (CIRS) - Georgetown University School of Foreign Service in Qatar, (2012).

[13] Saudi Aramco, Saudi Aramco - Our company - Who we are. Available at: http://www.saudiaramco.com/en/home.html\#our-company\%257C\%252Fen\%252Fhome\%252Fourcompany.baseajax.html Accessed: 11/09/2013, (2013).

[14] S. Jones, M. Tefe and S. Appiah-Opoku, "Proposed framework for sustainability screening of urban transport projects in developing countries: A case study of Accra, Ghana, Transportation Research Part A: Policy and Practice", ISSN 0965-8564, http://dx.doi.org/10.1016/j.tra.2013.01.003, vol. 49, (2013) March, pp. 21-34.

[15] (http://www.sciencedirect.com/science/article/pii/S0965856413000104).

[16] C. C. Wright and J. Egan, "De-marketing the car", Transport Policy, vol. 7, (2000), pp. 287-94. 